
A. Barison
G. D. Aquaro
C. Passino
M. Falorni
A. Balbarini
M. Lombardi
L. Pasquali
M. Emdin
G. Siciliano

\section{Cardiac magnetic resonance imaging and management of dilated cardiomyopathy in a Duchenne muscular dystrophy manifesting carrier}

Received: 29 February 2008

Received in revised form: 7 June 2008 Accepted: 7 July 2008

Published online: 27 February 2009

Sirs: Duchenne muscular dystrophy (DMD) is an X-linked recessive disorder caused by a deficiency of dystrophin in skeletal and cardiac

\footnotetext{
A. Barison, MD · A. Balbarini, MD

Cardiac Thoracic and Vascular Department University of Pisa

Via Paradisa 2

56124 Pisa, Italy

G. D. Aquaro, MD - C. Passino, MD .

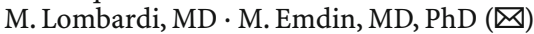

CNR, Gabriele Monasterio Foundation

and Institute of Clinical Physiology

National Research Council

Via Moruzzi 1

56124 Pisa, Italy

Tel.: +39-050/3152-189

Fax: +39-050/3152-109

Mobile: $+39-347 / 8062882$

E-Mail: emdin@ifc.cnr.it

C. Passino, MD

Scuola Superiore Sant'Anna

Piazza Martiri della Libertà 33

56127 Pisa, Italy

M. Falorni, MD - L. Pasquali, MD, PhD .

G. Siciliano, MD, PhD

Dept. of Neuroscience

Section of Neurology

University of Pisa

Via Roma 67

56126 Pisa, Italy
}

muscles. Most DMD boys initially present delayed motor milestones, elevated serum creatine kinase (CK), respiratory impairment and $25 \%$ of those surviving the age of 15 present dilated cardiomyopathy and arrhythmias $[3,4,8,10]$. Echocardiography describes left ventricular dysfunction, but cardiac magnetic resonance (CMR) can detect the earliest signs of cardiomyopathy: occult regional cardiac asynergy; tissue degeneration; fibrosis $[1,9,12]$. Standard therapy for heart failure is effective in DMD cardiomyopathy $[7,10]$.

Female carriers show a mosaic pattern of dystrophin-positive and dystrophin-negative muscular fibres. About $50 \%$ of patients present skeletal muscular symptoms and $18 \%$ present dilated cardiomyopathy, because of a "skewed Xinactivation", with most cells having an active faulty $\mathrm{X}$-chromosome $[5,6]$.

A 27-year old woman was referred to our hospital in 2005 because of fatigue, effort dyspnoea (NYHA class IIb), episodes of palpitations and near syncope. Two brothers with a typical history of DMD without heart involvement died in their teens due to respiratory failure. Her asymptomatic 6year old daughter had a mild increase of CK (640 U/L). DNA analysis revealed dystrophin gene deletion of exons 3-17. Electromyography showed small duration motor unit potentials and reduced amplitude interference pattern during voluntary contraction. In 2003, she had already been diagnosed with a dilated cardiomyopathy, with an echocardiographic ejection fraction (EF) of $40 \%$, treated discontinuously with carvedilol $6.25 \mathrm{mg}$ b.i.d. She was a smoker (5 cigarettes/d) and showed only calf pseudohypertrophy.

She had high plasmatic concentrations of CK (1745 U/L, n.v. 22269), normal levels of cardiac tro- ponin I $(0.02 \mathrm{ng} / \mathrm{mL}$, n.v. $<0.5 \mathrm{ng} /$ $\mathrm{mL})$, plasma renin activity $(1 \mathrm{ng} /$ $\mathrm{mL} / \mathrm{h}$, n.v. $0.2-2.8$ ) and noradrenaline $(306 \mathrm{pg} / \mathrm{mL}$, n.v. $<500)$, and borderline concentrations of aldosterone $(157 \mathrm{pg} / \mathrm{mL}$, n.v. $20-180)$ and NT-proBNP (142 ng/L, n.v. <157).

Her 24-hour ECG showed sinus rhythm, incomplete right bundle branch block, a paroxysmal supraventricular tachycardia and Lown class IV ventricular arrhythmias. Echocardiography confirmed the dilated cardiomyopathy (EF $33 \%)$. CMR showed left ventricular dilation (end-diastolic volume, EDV, $126 \mathrm{ml} / \mathrm{m}^{2}$, n.v. 56-99), diffuse hypokinesia (EF $35 \%$ ), with preserved left ventricular mass $(62 \mathrm{~g} /$ $\mathrm{m}^{2}$, n.v. 37-67) and right ventricular function (EDV $91 \mathrm{ml} / \mathrm{m}^{2}$, n.v. 48-103; EF $50 \%$ ) (Fig. 1 a). Moreover CMR showed small areas of gadolinium delayed enhancement, suggestive of intramyocardial fibrosis, in the lateral wall and in septal junctions (Fig. 1b). An intracardiac electrophysiological study revealed an inducible slowfast reciprocating tachycardia, treated by radio-frequency catheter ablation of the slow pathway, without sustained ventricular tachycardias. Carvedilol was uptitrated to $25 \mathrm{mg}$ b.i.d; ramipril $2.5 \mathrm{mg} / \mathrm{d}$ and spironolactone $25 \mathrm{mg} / \mathrm{d}$ were introduced. The patient then started a regular physical aerobic training program, 30-40 min cycloergometer sessions three times a week, at a work level under $60 \%$ of $\mathrm{VO}_{2 \max }$.

After discharge she reported a stable clinical status (NYHA class IIa). Two years later she still had increased CK (2051 U/L) and NTproBNP (238 ng/L), but slightly reduced plasmatic aldosterone $(92 \mathrm{pg} / \mathrm{mL})$, noradrenaline $(162 \mathrm{pg} /$ $\mathrm{mL})$ and renin activity $(0.81 \mathrm{ng} /$ $\mathrm{mL} / \mathrm{h}$ ). Her 24-hour ECG documented reduced ventricular arrhythmias without significant supraventricular arrhythmias. CMR showed a stable left ventricu- 

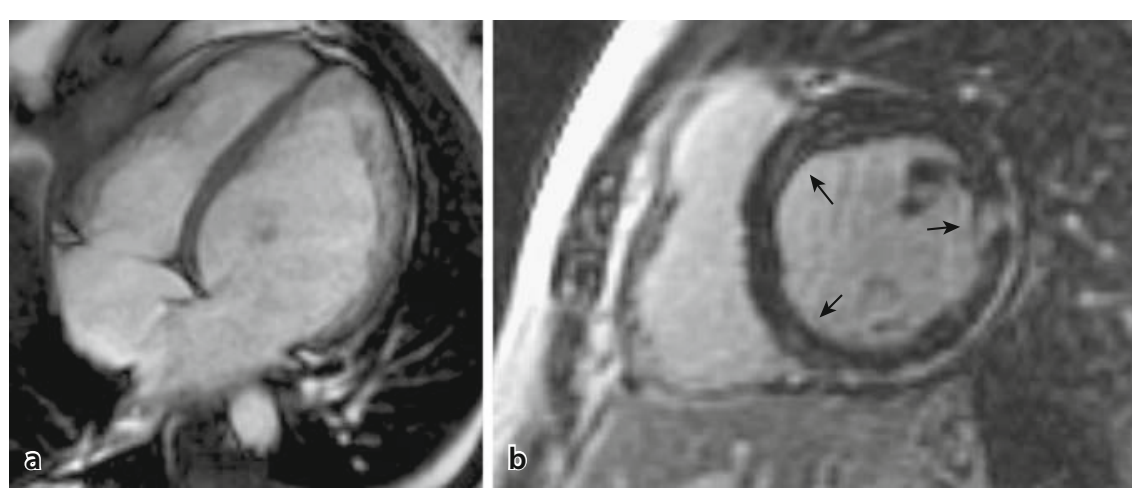

Fig. 1 a CMR (1.5 T, Signa CV/i GE Healthcare, Milwaukee, Wisconsin) steady-state free precession (SSFP) 4-chamber image of the heart, showing a mildly enlarged left ventricle with normal wall thickness. b CMR postcontrast T1-weighted inversion-recovery GRE short-axis view of the heart, showing areas of intramyocardial fibrosis (arrows) in the basal lateral wall and anteroseptal and inferoseptal junctions

lar dilation (EDV, $\left.128 \mathrm{ml} / \mathrm{m}^{2}\right)$, an improved systolic dysfunction (EF $42 \%)$, normal ventricular mass $\left(67 \mathrm{~g} / \mathrm{m}^{2}\right)$ and right ventricular function (EDV $101 \mathrm{ml} / \mathrm{m}^{2} ; \mathrm{EF}$ $51 \%)$; the fibrotic areas were unchanged.

This case report highlights the likely occurrence of cardiomyopathy and arrhythmias in DMD carriers despite the minimal involvement of skeletal muscles, probably related to the different mechanisms of dystrophin gene regulation in cardiac and skeletal muscles [2]. The absence of significant neurohormonal activation agrees with previous observations [11]. CMR allowed a precise quantification of cardiac morphology and function; gadolinium revealed "spotty" intramyocardial fibrosis, probably deriving either from the chimerical distribution of "healthy" and "diseased" cardiomyocytes or from the heterogeneous distribution of myocardial wall stress damage.

Moreover, our case shows the beneficial effect of an optimized medical therapy on symptoms and cardiac function, compared to the natural progression of the disease.

Conflict of interest The authors declare no conflict of interest.

\section{References}

1. Ashford MW, Liu W, Lin SJ, Abraszewski P, Caruthers SD, Connolly AM, Yu X, Wickline SA (2005) Occult cardiac contractile dysfunction in dystrophindeficient children revealed by cardiac magnetic resonance strain imaging. Circulation 112:2462-2467

2. Bastianutto C, Bestard JA, Lahnakoski $\mathrm{K}$, Broere D, De Visser M, Zaccolo M, Pozzan T, Ferlini A, Muntoni F, Patarnello T, Klamut HJ (2001) Dystrophin muscle enhancer 1 is implicated in the activation of non-muscle isoforms in the skeletal muscle of patients with Xlinked dilated cardiomyopathy. Hum Mol Genet 10:2627-2635

3. Bushby K, Bourke J, Bullock R, Eagle M, Gibson M, Quinby J (2005) The multidisciplinary management of Duchenne muscular dystrophy. Current Paediatrics 15:292-300

4. Groh WJ, Zipes DP (2005) Neurological disorders and cardiovascular diseases. In: Braunwald E (ed) Heart diseases, $7^{\text {th }}$ edition. Elsevier Saunders, Philadelphia, pp 2145-2160
5. Hoogerwaard EM, van der Wouw PA, Wilde AAM, Bakker E, Ippel PF, Oosterwijk JC, Majoor-Krakauer DF, van Essen AJ, Leschot NJ, de Visser M (1999) Cardiac involvement in carriers of Duchenne and Becker muscular dystrophy. Neuromuscul Disord 9: 347-351

6. Hoshino S, Ohkoshi N, Watanabe M, Shoji S (2000) Immunohistochemical staining of dystrophin on formalinfixed paraffin-embedded sections in Duchenne/Becker muscular dystrophy and manifesting carriers of Duchenne muscular dystrophy. Neuromuscul Disord 10:425-429

7. Kinali M, Robinson R, Sagi L, Nihoyannopoulos P, Manzur A, Muntoni F (2007) The role of ACE inhibitor therapy in presymptomatic cardiomyopathy in Duchenne muscular dystrophy. Neuromuscul Disord 17:816

8. Kirchmann C, Kececioglu D, Korinthenberg R, Dittrich S (2005) Echocardiographic and electrocardiographic findings of cardiomyopathy in Duchenne and Becker-Kiener muscular dystrophies. Pediatr Cardiol 26:66-72

9. Mavrogeni S, Tzelepis GE, Athanasopoulos G, Maounis T, Douskou M, Papavasiliou A, Cokkinos DV (2005) Cardiac and sternocleidomastoid muscle involvement in Duchenne muscular dystrophy. Chest 127:143-148

10. Mc Nelly EM (2007) New approaches in the therapy of cardiomyopathy in muscular dystrophy. Ann Rev Med 58:75-88

11. Schade van Westrum SM, Dekker L, Endert E, de Haan RJ, Wilde AAM, de Visser M, van der Kooi AJ (2006) NTproBNP is not associated with dilated cardiomyopathy in Becker and Duchenne muscular dystrophies. Neuromuscul Disord 16:698-669

12. Silva MC, Meira ZM, Gurgel Giannetti J, da Silva MM, Campos AF, Barbosa Mde M, Starling Filho GM, Ferreira Rde A, Zatz M, Rochitte CE (2007) Myocardial delayed enhancement by magnetic resonance imaging in patients with muscular dystrophy. J Am Coll Cardiol 49:1874-1879 